\title{
Transcriptome profiling of porcine testis tissue reveals genes related to sperm hyperactive motility
}

\author{
Maren van Son ${ }^{1 *}$ DD, Nina Hårdnes Tremoen ${ }^{2,3}$, Ann Helen Gaustad ${ }^{1,2}$, Dag Inge Våge ${ }^{3}$,
} Teklu Tewoldebrhan Zeremichael ${ }^{2}$, Frøydis Deinboll Myromslien² and Eli Grindflek

\begin{abstract}
Background: Sperm hyperactive motility has previously been shown to influence litter size in pigs, but little is known about the underlying biological mechanisms. The aim of this study was to use RNA sequencing to investigate gene expression differences in testis tissue from Landrace and Duroc boars with high and low levels of sperm hyperactive motility. Boars with divergent phenotypes were selected based on their sperm hyperactivity values at the day of ejaculation (day 0) (contrasts (i) and (ii) for Landrace and Duroc, respectively) and on their change in hyperactivity between day 0 and after $96 \mathrm{~h}$ liquid storage at $18^{\circ} \mathrm{C}$ (contrast (iii)).

Results: RNA sequencing was used to measure gene expression in testis. In Landrace boars, 3219 genes were differentially expressed for contrast (i), whereas 102 genes were differentially expressed for contrast (iii). Forty-one differentially expressed genes were identified in both contrasts, suggesting a functional role of these genes in hyperactivity regardless of storage. Zinc finger DNLZ was the most up-regulated gene in contrasts (i) and (iii), whereas the most significant differentially expressed gene for the two contrasts were ADP ribosylation factor ARFGAP1 and solute carrier SLC4OA1, respectively. For Duroc (contrast (ii)), the clustering of boars based on their gene expression data did not reflect their difference in sperm hyperactivity phenotypes. No results were therefore obtained for this breed. A case-control analysis of variants identified in the Landrace RNA sequencing data showed that SNPs in NEU3, CHRDL2 and HMCN1 might be important for sperm hyperactivity.
\end{abstract}

Conclusions: Differentially expressed genes were identified in Landrace boars with high and low levels of sperm hyperactivity at the day of ejaculate collection and high and low change in hyperactivity after $96 \mathrm{~h}$ of sperm storage. The results point towards important candidate genes, biochemical pathways and sequence variants underlying sperm hyperactivity in pigs.

Keywords: Sperm hyperactivity, Hyperactive motility, Testis, Gene expression, Pig, RNA sequencing

\footnotetext{
* Correspondence: maren.van.son@norsvin.no

${ }^{1}$ Norsvin SA, 2317 Hamar, Norway

Full list of author information is available at the end of the article
}

C C The Author(s). 2020 Open Access This article is licensed under a Creative Commons Attribution 4.0 International License, which permits use, sharing, adaptation, distribution and reproduction in any medium or format, as long as you give appropriate credit to the original author(s) and the source, provide a link to the Creative Commons licence, and indicate if changes were made. The images or other third party material in this article are included in the article's Creative Commons licence, unless indicated otherwise in a credit line to the material. If material is not included in the article's Creative Commons licence and your intended use is not permitted by statutory regulation or exceeds the permitted use, you will need to obtain permission directly from the copyright holder. To view a copy of this licence, visit http://creativecommons.org/licenses/by/4.0/ The Creative Commons Public Domain Dedication waiver (http://creativecommons.org/publicdomain/zero/1.0/) applies to the data made available in this article, unless otherwise stated in a credit line to the data. 


\section{Background}

The use of artificial insemination (AI) is crucial for efficient pig production and proper evaluation of semen quality is essential for high quality AI. Microscopic evaluation of ejaculates is a commonly used method but is subjective and not able to distinguish between subpopulations of spermatozoa with different motility characteristics [1]. Computer-Assisted Semen Analysis (CASA) provides accurate and objective evaluations of many sperm characteristics such as motility, morphology and concentration [1], and has been used in several species to predict fertility outcome [2]. Ejaculated mammalian spermatozoa are not able to fertilize an oocyte before capacitation has occurred, a process where they acquire hyperactive motility and other modifications that facilitate fertilization [3]. The hyperactive motility is characterized by a vigorous and non-linear swimming pattern, which help the spermatozoa to penetrate the zona pellucida [4]. CASA recognizes the hyperactive motility pattern as high curvilinear velocity and amplitude of the lateral head movement and low linear trajectory [5]. Hyperactive swimming pattern varies between species, and for boar spermatozoa the CASA thresholds have been related to curvilinear velocity (VCL), lateral head displacement (ALH), linearity (LIN) and wobble (WOB) [5]. The change in swimming pattern towards hyperactivity has been shown to require calcium, increased $\mathrm{pH}$ and ATP production [4].

In our previous study, several parameters defining hyperactive motility was correlated to the total number of piglets born, and breed differences were found for sperm motility characteristics [6]. Whereas Landrace developed more hyperactivity during storage, Duroc showed a large portion of sperm cells with hyperactive swimming pattern already at the day of ejaculate collection and no significant increase after storage [6]. Due to factors such as long-distance shipment, the semen doses are often stored for 48 to $96 \mathrm{~h}$ before used for insemination. Differences in hyperactive motility between the day of semen collection and after storage is of interest. The sperm cells' capability of obtaining and maintaining hyperactive motility is a prerequisite for fertilization and if this occurs too early, there is a risk that the sperm cells deplete their energy store and die before they reach the oocyte [3].

Previous studies on the genomics underlying sperm hyperactive motility have focused on a limited number of candidate genes. A family of CatSper (cation channel of sperm) genes has been associated with different sperm quality parameters, including hyperactive motility [reviewed by 7]. CatSpers are voltage-dependent, calcium ion selective and $\mathrm{pH}$-sensitive ion channels that controls entry of calcium ions into sperm cells [7, 8]. Other candidate genes have been associated to sperm hyperactivation in other species, like a family of $\beta$ defensin genes in mouse [9]. A proteomic study of boar spermatozoa have identified several proteins important for capacitation, belonging to pathways such as tricarboxylic acid cycle, glutathione metabolism, adipocytokine signaling and insulin action [10].

Before the spermatozoa can acquire hyperactive motility and fertilize an oocyte, it must undergo several different processes within testes including production, maturation and ejaculation. In this study, we wanted to examine how gene expressions in testis are associated with hyperactivity in ejaculated spermatozoa, as production and maturation of spermatozoa takes place in testis. Testis tissue samples were therefore collected from Landrace and Duroc boars where spermatozoa had been examined for degree of hyperactivity at the day of ejaculation (day 0) and after $96 \mathrm{~h}$ storage. Samples with high and low sperm hyperactive motility at day 0 and high and low change in level of hyperactivity between day 0 and $96 \mathrm{~h}$ storage were then used for transcriptome sequencing and facilitated the identification of differentially expressed genes and pathways.

\section{Results}

\section{Sperm hyperactive motility data}

Transcriptome sequencing was performed to analyze gene expression in testis tissue from Landrace and Duroc boars with different levels of sperm hyperactive motility. Three different contrasts were prepared in this study: (i) high versus low hyperactivity at ejaculation (day 0) in Landrace, (ii) high versus low hyperactivity at ejaculation (day 0) in Duroc, and (iii) high versus low change in levels of hyperactivity between day 0 and $96 \mathrm{~h}$ storage in Landrace (Table 1). In Duroc, a large proportion of the sperm cells were already hyperactive at day 0 , and there were not enough extreme animals to make a contrast after $96 \mathrm{~h}$ storage. The mean $( \pm \mathrm{SD})$ hyperactivity values for the contrasts were $14.5 \%( \pm 1.7)(n=4)$ and $1.6 \%( \pm 0.3)(n=4)$ for contrast (i), 26.7\% $( \pm 1.7)(n=5)$ and $6.3 \%( \pm 2.7)(n=4)$ for contrast (ii), and $15.0 \%( \pm 3.0)$ $(n=3)$ and $2.7 \% \quad( \pm 0.6) \quad(n=4)$ for contrast (iii), respectively.

\section{Testis transcriptome sequence data}

The average number of $100 \mathrm{bp}$ single reads generated by RNA sequencing across the samples was 98 million, ranging from 65 to 196 million (Table 1). Trimmomatic [11] removed between $0.38-0.7 \%$ of the reads, and $96.44 \%$ of the remaining high-quality reads were successfully mapped to the pig genome build 11.1 [12]. For the different contrasts, $82-83 \%$ of the 25,880 pig genes had at least one count in at least one of the samples and were included in the differential expression analysis. 
Table 1 Sperm hyperactivity measurements for the different boars included in this study

\begin{tabular}{|c|c|c|c|c|c|}
\hline Group & Boar & n (ejaculates) & mean \%hyperactivity & SD \%hyperactivity & Read depth \\
\hline \multirow[t]{4}{*}{ Landrace low day 0} & L1 & 3 & 1.9 & 0.2 & 77.6 \\
\hline & L2 & 4 & 1.2 & 0.7 & 107.7 \\
\hline & L3 & 3 & 1.6 & 0.6 & 119.9 \\
\hline & $\llcorner 4$ & 3 & 1.6 & 0.2 & 87.7 \\
\hline \multirow[t]{4}{*}{ Landrace high day 0} & L5 & 3 & 16.4 & 7.3 & 94.6 \\
\hline & L6 & 3 & 13.6 & 3.2 & 113.6 \\
\hline & L7 & 4 & 15.5 & 3.1 & 127.4 \\
\hline & L8 & 4 & 12.6 & 3.1 & 139.7 \\
\hline \multirow[t]{4}{*}{ Landrace low change $96 \mathrm{~h}$ vs. day 0} & L9 & 5 & 3.3 & 2.1 & 80.0 \\
\hline & L10 & 3 & 2.1 & 1.4 & 78.9 \\
\hline & L11 & 4 & 2.3 & 0.6 & 107.7 \\
\hline & $\mathrm{L} 12$ & 3 & 3.0 & 2.8 & 71.2 \\
\hline \multirow[t]{3}{*}{ Landrace high change $96 \mathrm{~h}$ vs. day 0} & L13 & 3 & 11.7 & 7.0 & 121.4 \\
\hline & L14 & 4 & 17.3 & 9.0 & 127.4 \\
\hline & L15 & 3 & 16.2 & 3.7 & 84.6 \\
\hline \multirow[t]{4}{*}{ Duroc low day 0} & D1 & 3 & 3.7 & 0.7 & 68.5 \\
\hline & D2 & 3 & 7.0 & 2.8 & 72.0 \\
\hline & D3 & 4 & 9.8 & 2.4 & 77.8 \\
\hline & D4 & 3 & 4.7 & 1.5 & 86.7 \\
\hline \multirow[t]{5}{*}{ Duroc high day 0} & D5 & 3 & 23.6 & 7.9 & 65.2 \\
\hline & D6 & 4 & 23.8 & 3.9 & 74.6 \\
\hline & D7 & 3 & 27.9 & 4.0 & 76.2 \\
\hline & D8 & 3 & 27.4 & 1.4 & 121.2 \\
\hline & D9 & 3 & 27.9 & 8.7 & 195.7 \\
\hline
\end{tabular}

The boars of contrast (i) (L1-L8), (iii) (L9-L15) and (ii) (D1-D9) are presented with the number of ejaculates, mean and standard deviation (SD) for \%hyperactivity in the ejaculates. Read depth is number of sequenced reads per sample in million

Normalization in edgeR adjusted for differences in sequencing depths as represented by differing library sizes.

\section{Differential expression}

Contrasts (i) and (iii) showed similarity in gene expression patterns when performing cluster analysis by multidimensional scaling (Fig. $1 \mathrm{~A}$ and B). Differentially expressed genes are displayed in heat maps (Fig. $2 \mathrm{~A}$ and B), showing similar trends for the high and low groups. Contrast (ii), on the other hand, did not cluster as expected based on sperm hyperactivity measurements as described above (Fig. 1C). No significant results could therefore be obtained from the Duroc contrast (ii).

For contrast (i), high versus low hyperactivity on day 0 in Landrace, 3219 genes were found differentially expressed $(F D R<0.05)$ [see Additional file 1]. Of these, 870 genes were down-regulated in the high hyperactivity group whereas the rest were upregulated. The most significant differentially expressed gene was ADP ribosylation factor GTPase activating protein 1 (ARFGAP1) (FDR $=1.2 \mathrm{e}-05)$. The most up- regulated gene in the high hyperactivity group was DNL-type zinc finger $(D N L Z)(\log F C=2.7)$, whereas the most down-regulated gene was novel gene ENSSSCG00000037477 (NCBI description: tetratricopeptide repeat protein 37-like; $\log F C=-3.0$ ).

For contrast (iii), high versus low change in levels of hyperactivity between day 0 and $96 \mathrm{~h}$ storage in Landrace, 102 genes were differentially expressed $(F D R<0.05)$ [see Additional file 2]. Of these, 33 genes were up-regulated in the high hyperactivity group whereas 69 were down-regulated, and the most significant gene was solute carrier family 40 member 1 (SLC40A1) $($ FDR =9.7e-04). In the high hyperactivity group, the most up-regulated gene was the same as in contrast (i): $D N L Z(\log F C=1.9)$, whereas the most down-regulated gene was calcium dependent secretion activator $(C A D P S)(\log \mathrm{FC}=-2.0)$.

Between contrasts (i) and (iii), 41 differentially expressed genes were found in common (Fig. 1D and Table 2). The most significant common gene was DNLZ (Fig. 3). 


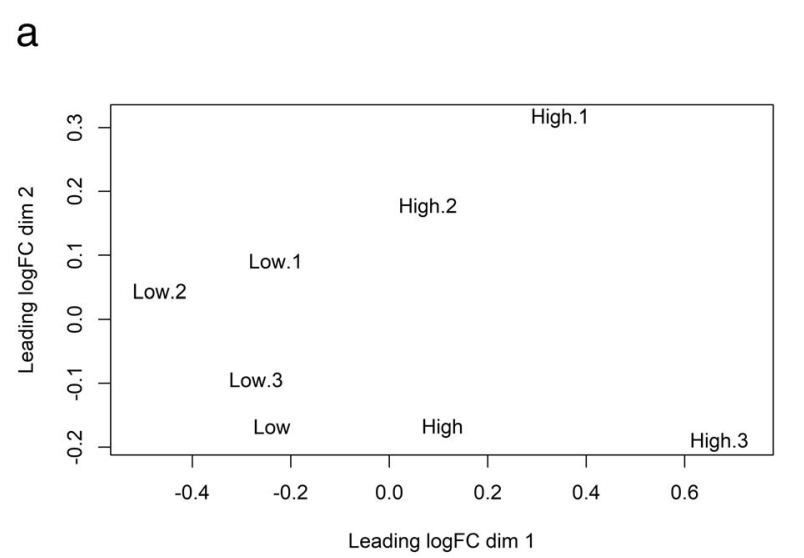

b

C

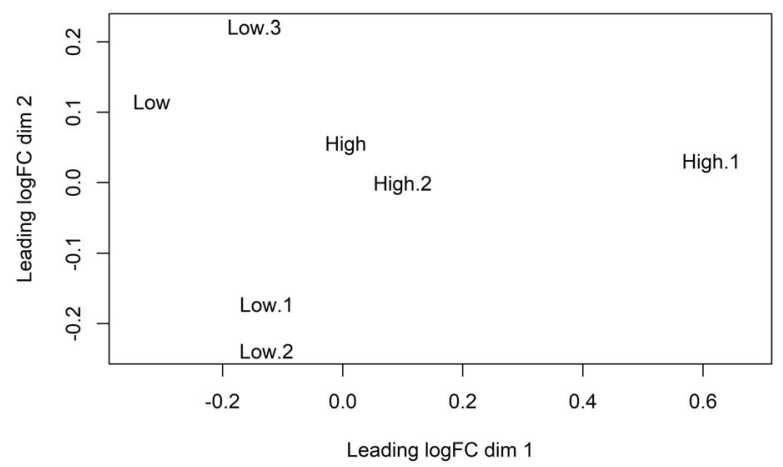

d
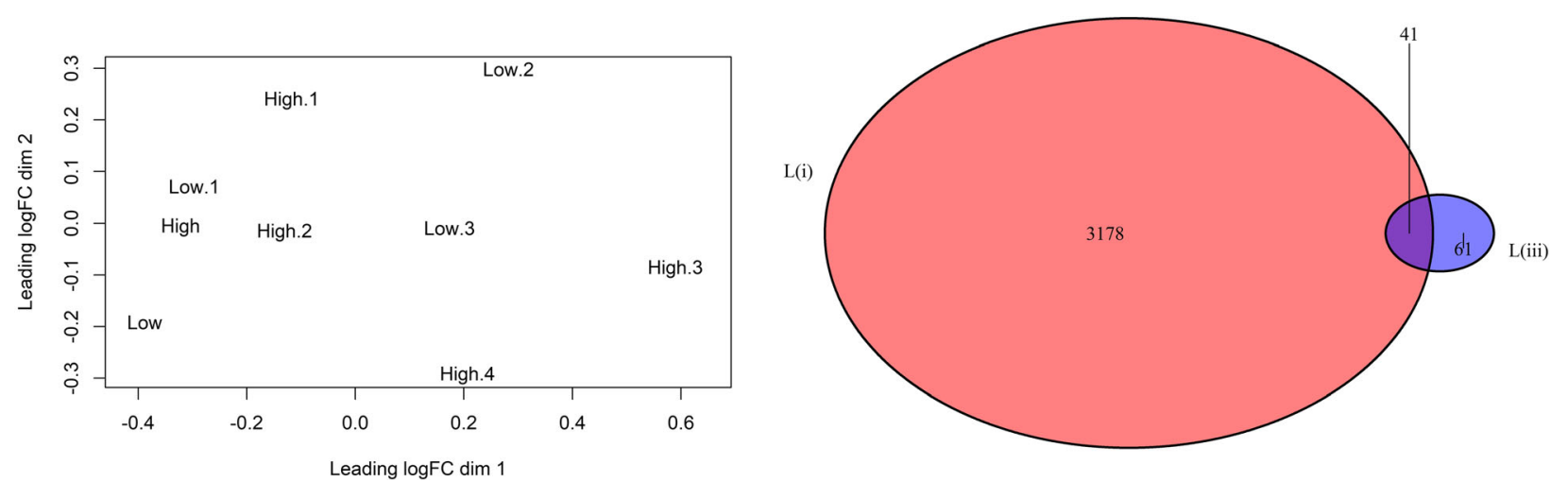

Fig. 1 Multidimensional scaling (MDS) plots and Venn diagram for the gene expression data. a and $\mathbf{b}$ are MDS plots of contrasts (i) and (iii) in Landrace, respectively, whereas $\mathbf{c}$ is of contrast (ii) in Duroc. $\mathbf{d}$ shows the number of differentially expressed genes for contrast (i) and (iii) with their overlap

\section{Gene ontology}

Over-represented pathways among the differentially expressed genes were identified by gene ontology analysis. For contrast (i), 12 pathways were over-represented (Table 3), and the most significant pathways include the "extracellular exosome" (GO:0070062), "cytoplasm" (GO: 0005737) and "in utero embryonic development" (GO: 0001701). Furthermore, all genes belonging to the biological process pathway "establishment or maintenance of transmembrane electrochemical gradient" (GO: 0010248) were differentially expressed: ATPase gene members ATP1A1, ATP1A2, ATP1B2, ATP4A and BCL2 associated $\mathrm{X}$, apoptosis regulator $(B A X)$. Eight of the nine genes in the cellular component "GATOR2 complex" (GO:0061700) were also differentially expressed: cytosolic arginine sensor for mTORC1 subunit 1 (CASTOR1), meiosis regulator for oocyte development (MIOS), SEC13 homolog nuclear pore and COPII coat complex component (SEC13), sestrins SESN1 and SESN2, KICSTOR complex subunit (SZT2), and WD (tryptophan-aspartic acid dipeptide) repeat domains WDR24 and WDR59.
For contrast (iii), seven pathways were overrepresented (Table 4), and the most significant pathways include the cellular component "extracellular space" (GO:0005615), "extracellular region" (GO:0005576) and "adenosine catabolic process" (GO:0006154). None of the overrepresented pathways in contrast (i) and (iii) were in common.

\section{Variant calling}

SNP detection in the sequence data of the Landrace animals from contrasts (i) and (iii) identified 103,161 filtered, high-quality variants (Table 5 and Additional file 3). Of these variants, $75 \%$ had existing dbSNP entries. The importance of the detected SNPs was investigated by a casecontrol analysis and by localization in differentially expressed genes.

In search of SNPs that may affect levels of hyperactivity, a case-control analysis was performed between the high and low groups within each contrast. Genotype frequencies of 278 and 19 variants were significantly different between the high and low groups of contrasts (i) and (iii), respectively (Additional file 4). None of these SNPs 

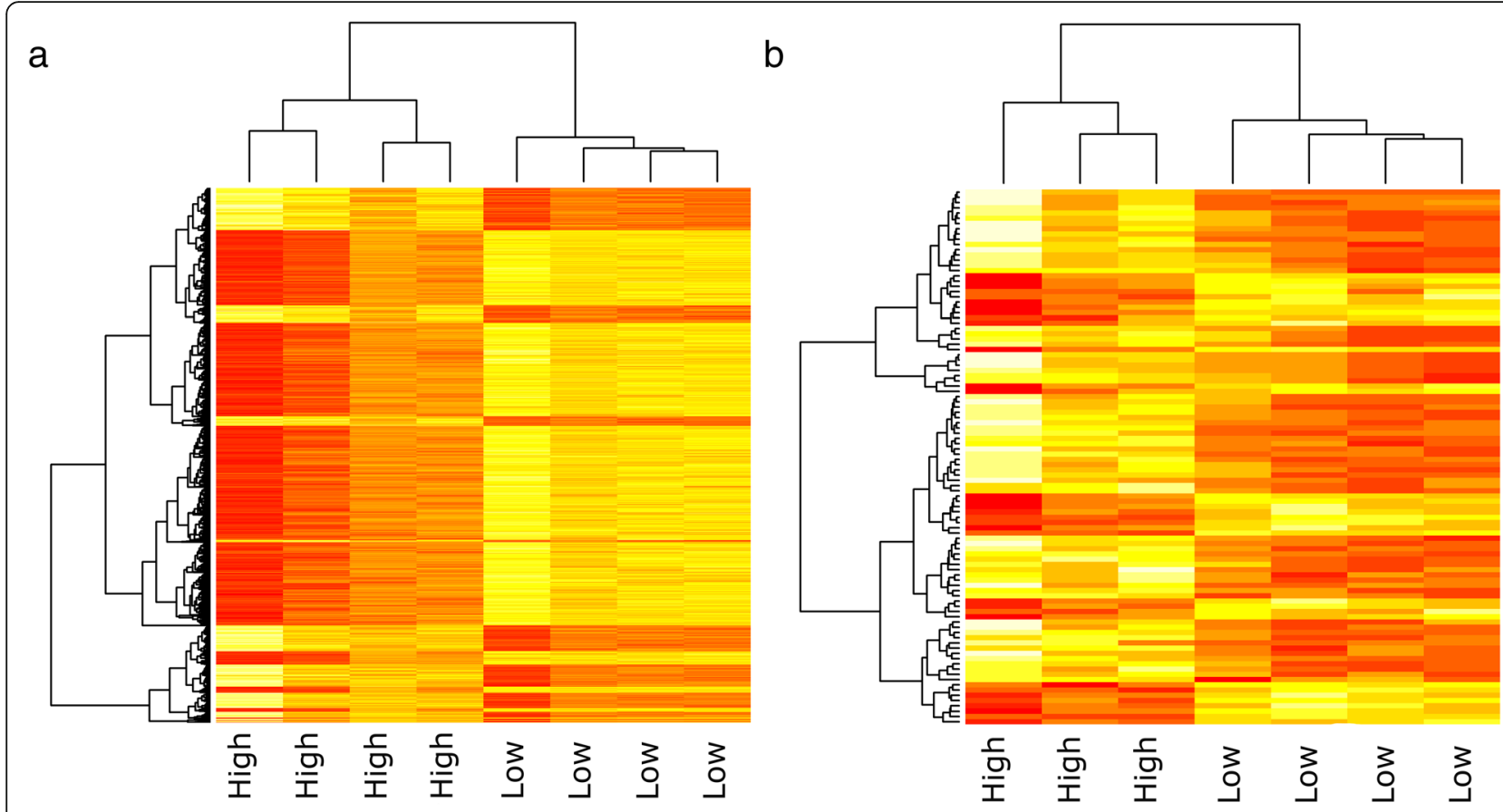

Fig. 2 Heatmap for hierarchical clustering of differential gene expression. Each row of the grid corresponds to a different gene and each column represents a sample. The up-regulated (red) and down-regulated (yellow) genes were distinguished between the high versus low sperm hyperactivity groups in a) contrast (i) high versus low hyperactivity at the day of ejaculation in Landrace and b) contrast (iii) high versus low change in levels hyperactivity between day 0 and $96 \mathrm{~h}$ storage in Landrace

had a predicted high impact according to Ensembl variant effect predictor (VEP), however, for contrast (i), 18 SNPs had a predicted moderate or low impact, and for all these SNPs the alternate allele was only present in one of the animal groups (high or low sperm hyperactivity). Thirteen of these 18 SNPs were located in neuraminidase 3 (NEU3) and one of these, rs318364485, was predicted to be deleterious with a SIFT score of 0.05 . Further, two of the 18 SNPs were located in chordin like 2 (CHRDL2) and hemicentin 1 (HMCN1), respectively.

Of the identified 103,161 filtered, high-quality variants, 16 SNPs located in differentially expressed genes of contrast (i) were predicted to have a high impact (Ensembl VEP) (Table 5 and Additional file 5). These 16 SNPs were located in 15 different genes: cilia and flagella associated protein 65 (CFAP65), peptidylprolyl isomerase $\mathrm{G}$ (PPIG), gametogenetin binding protein 2 (GGNBP2), protein arginine methyltransferase 2 (PRMT2), calcium binding protein 39 (CAB39), RuvB like AAA ATPase 1 (RUVBL1), coiled-coil domain containing 187 (CCDC187), NUT midline carcinoma family member 1 (NUTM1), Rap associating with DIL domain (RADIL), angiogenic factor with G-patch and FHA domains 1 (AGGF1), ribonucleoprotein PTB binding 1 (RAVER1), ribosomal protein S9 (RPS9) and three uncharacterized genes. Of the 16 high impact SNPs, six had existing rs-IDs, and of the ten remaining, eight could be verified in an independent whole-genome sequencing dataset from the same Landrace population [13]. The SNPs in CAB39 and AGGF1 could not be verified in this dataset. When the detected 103,161 filtered, high-quality variants were compared to the results of contrast (iii), no high impact SNPs were localized in the differentially expressed genes.

\section{Discussion}

Transcriptome sequencing was conducted to elucidate genes and pathways associated with sperm hyperactive motility in two pig breeds, Landrace and Duroc. Hyperactive motility of sperm cells is important for fertilization of an oocyte; however, if acquired too early, the sperm cells drain their energy and risk not reaching the oocyte. In this study, we therefore included two contrasts in Landrace: (i) high versus low levels of sperm hyperactivity at the day of ejaculation (day 0) and (iii) high versus low change in levels of sperm hyperactivity between day 0 and $96 \mathrm{~h}$ storage. In Norway, porcine liquid diluted semen is recommended to be used within $96 \mathrm{~h}$ after collection, hence this storage limit of contrast (iii). We also tried to include a third contrast, day of ejaculation (day 0) in Duroc (ii), however, this was not successful and is discussed in the section "Breed differences" below. Generally, it is of interest to identify putative biomarkers for boar fertility and no studies in the past have looked at testis gene expression and how it is 


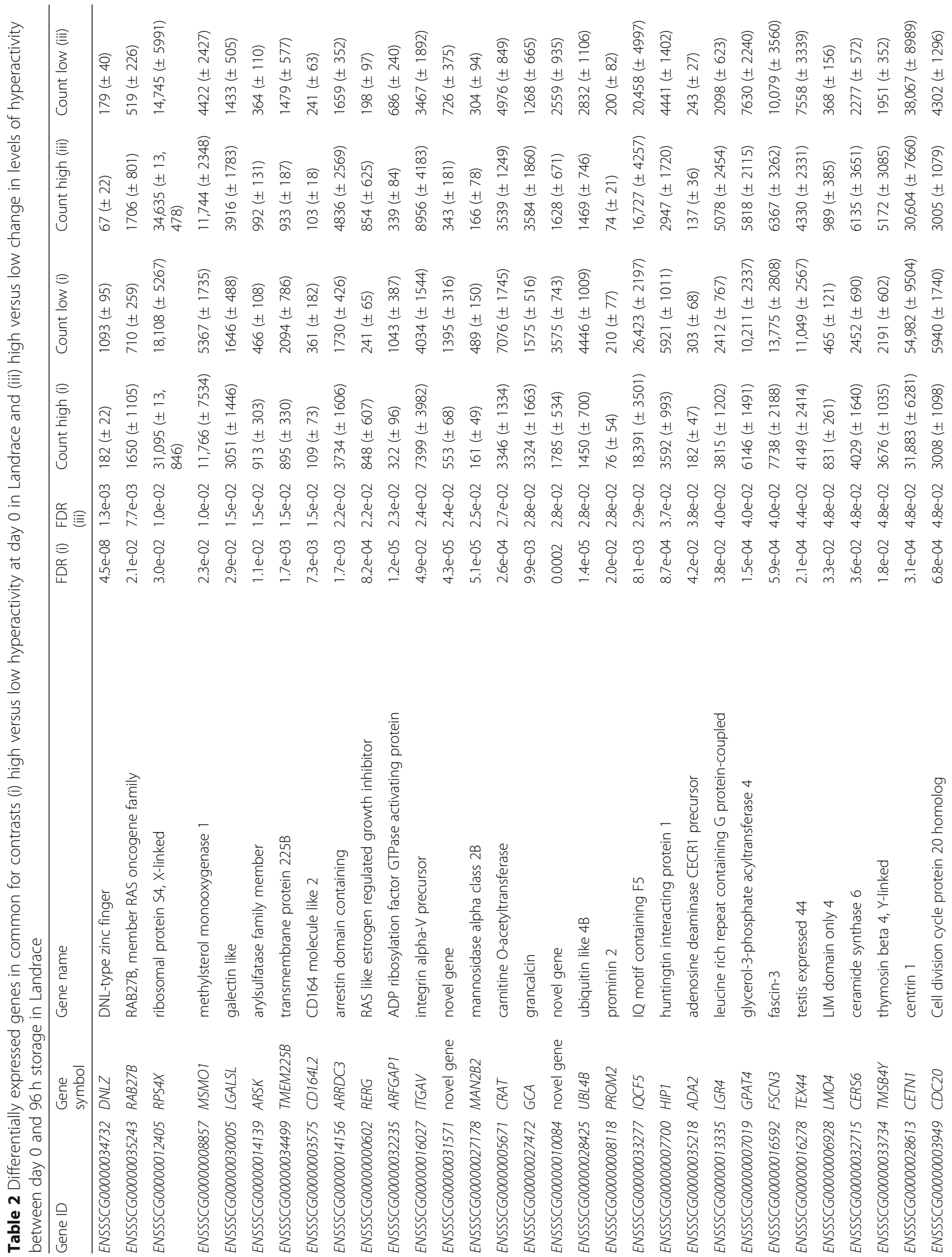




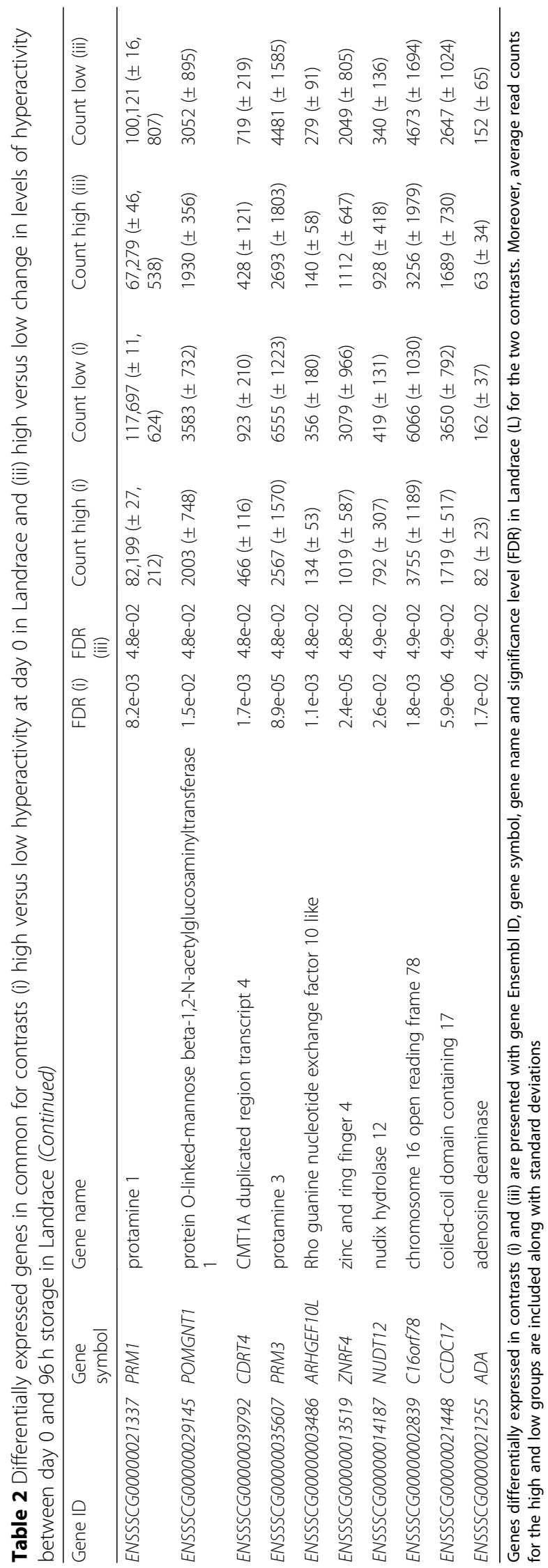




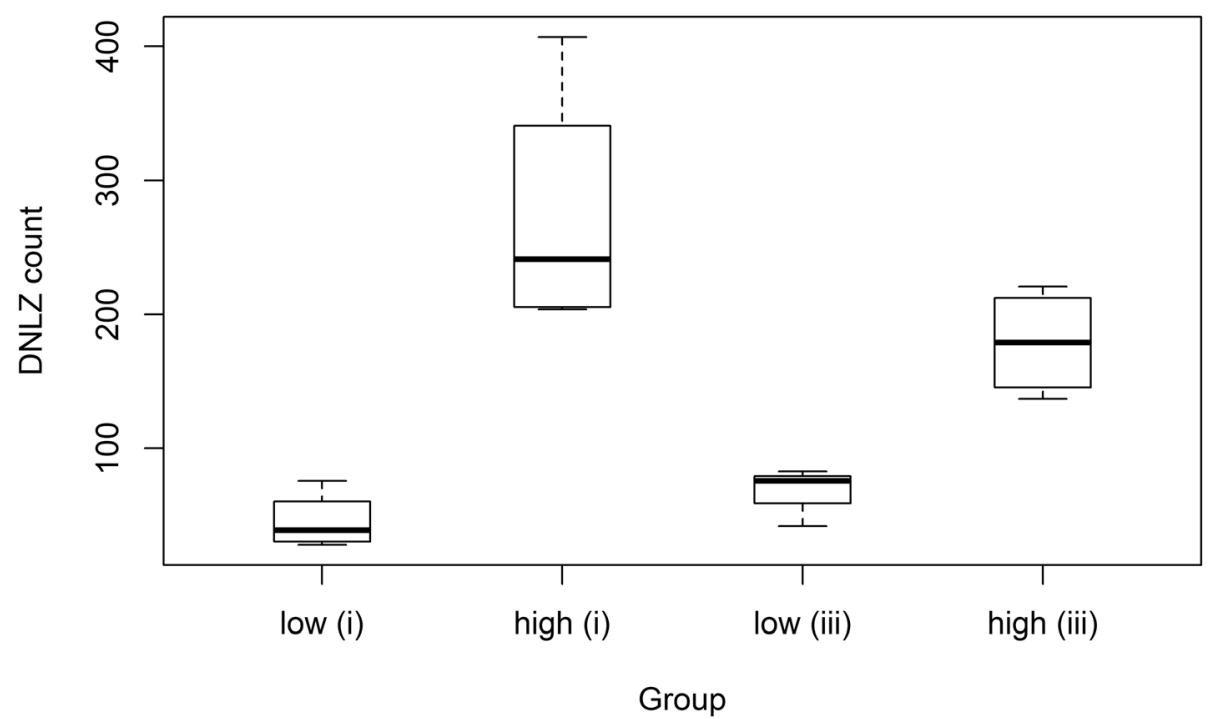

Fig. 3 Boxplot showing the differential expression of DNLZ. The most significant gene in common for the Landrace contrasts (i) high versus low hyperactivity at the day of ejaculation in Landrace and (iii) high versus low change in levels hyperactivity between day 0 and $96 \mathrm{~h}$ storage in Landrace was DNLZ. The read counts for the high and low groups of animals in these two contrasts are plotted and box edges represents the upper and lower quartile with the median value shown as a bold line in the middle of the box. Whiskers represent 1.5 times the quartile of the data

associated with sperm hyperactive motility. Each of the groups within the contrasts consisted of a limited set of animals $(n=3-5)$, which could affect our results by introducing spurious associations. Moreover, individual differences in seminal plasma content was not taken into account in the current study. Seminal plasma is reported to contain decapacitation factors and seems to inhibit the development of hyperactivated spermatozoa [14]. Further, proteins in seminal plasma have been reported to keep the spermatozoa progressively motile, viable and acrosome intact during storage [15]. This means that the results of both the contrast at the day of ejaculation and the contrast looking at difference in hyperactivity after storage could be affected by individual variation in seminal plasma content.

Genes important for hyperactivity regardless of storage Of the 3219 differentially expressed genes in contrast (i) and the 102 differentially expressed genes in contrast (iii), 41 were in common, suggesting that these genes are important for sperm hyperactive motility both initially and after storage. The most up-regulated gene in the

Table 3 Gene ontology (GO) functional enrichment analysis for the differentially expressed genes for hyperactivity at day 0 in Landrace

\begin{tabular}{llllll}
\hline Category & Term & Description & $P$-value & DE counts & Total in category \\
\hline CC & GO:0070062 & extracellular exosome & $6.58 E-06$ & 409 & 1371 \\
CC & GO:0005737 & cytoplasm & $1.67 E-05$ & 616 & 2157 \\
BP & GO:0001701 & in utero embryonic development & $2.73 E-05$ & 52 & 123 \\
MF & GO:0045296 & cadherin binding & $3.68 E-05$ & 68 & 174 \\
MF & GO:0000166 & nucleotide binding & $5.37 E-05$ & 190 & 591 \\
CC & GO:0005925 & focal adhesion & $6.80 E-05$ & 79 & 213 \\
CC & GO:0061700 & GATOR2 complex & $1.17 E-04$ & 8 & 9 \\
MF & GO:0005524 & ATP binding & $2.68 E-04$ & 242 & 792 \\
BP & GO:0060048 & cardiac muscle contraction & $2.89 E-04$ & 11 & 16 \\
CC & GO:0005634 & nucleus & $2.98 E-04$ & 715 & 2589 \\
CC & GO:0005813 & centrosome & $7.63 E-04$ & 103 & 310 \\
BP & GO:0010248 & establishment or maintenance of transmembrane electrochemical gradient & $9.37 \mathrm{E}-04$ & 5 & 5
\end{tabular}

Gene ontology results are presented with category (CC cellular component, $B P$ biological process, $M F$ molecular function), term, description, significant level ( $p$ value), gene count in differentially expressed genes (DE) and total number of genes in category 
Table 4 Gene ontology (GO) functional enrichment analysis for the differentially expressed genes for change in hyperactivity between day 0 and $96 \mathrm{~h}$ storage in Landrace

\begin{tabular}{|c|c|c|c|c|c|}
\hline Category & Term & Description & $P$-value & DE counts & Total in category \\
\hline CC & GO:0005615 & extracellular space & 2.37E-05 & 12 & 360 \\
\hline CC & GO:0005576 & extracellular region & 2.17E-04 & 9 & 247 \\
\hline BP & GO:0006154 & adenosine catabolic process & $2.31 \mathrm{E}-04$ & 2 & 3 \\
\hline CC & GO:0009897 & external side of plasma membrane & 4.33E-04 & 5 & 88 \\
\hline MF & GO:0005125 & cytokine activity & 4.60E-04 & 3 & 21 \\
\hline BP & GO:0071985 & multivesicular body sorting pathway & 7.27E-04 & 2 & 6 \\
\hline CC & GO:0032585 & multivesicular body membrane & 9.55E-04 & 2 & 6 \\
\hline
\end{tabular}

Gene ontology results are presented with category (CC cellular component, BP biological process, MF molecular function), term, description, significant level ( $p$ value), gene count in differentially expressed genes (DE) and total number of genes in category

high hyperactivity group of both contrasts was $D N L Z$, suggesting an important function in sperm hyperactivity in Landrace. DNLZ, also known as $H E P$ and $H E P 1$, is a zinc finger protein that is known to be important for regulation of HSPA9 ATPase activity in human by enhancing the rate of ATP hydrolysis [16, 17]. HSPA9 seems to be implicated in the maturity and fertilizing ability of spermatozoa [18] and was also differentially expressed in a proteomic study for human sperm motility [19]. Whether an increased HSPA9 ATPase activity by $D N L Z$ is the link to sperm hyperactive motility needs to be further investigated.
Adenosine deaminases $A D A$ and $A D A 2$ were differentially expressed in contrasts (i) and (iii), and the gene ontology term "adenosine catabolic process" was significant for contrast (iii). Previous studies have shown that adenosine enhances sperm capacitation and motility through ADA receptors [20-22]. This is interesting as capacitation is necessary for hyperactivation of sperm cells and could explain our results. Other genes in common for contrasts (i) and (iii) that have previously been associated to sperm motility are huntington interacting protein 1 gene (HIP1), protamines PRM1 and PRM3, transmembrane protein 225B (TMEM225B) and fascin-3

Table 5 Effects of putative SNPS

\begin{tabular}{|c|c|c|c|c|}
\hline SNP effect & All dataset & Joined with (i) & Joined with (iii) & Common (i) and (iii) \\
\hline $3^{\prime} U T R$ & 16,507 & 1665 & 72 & 4 \\
\hline $5^{\prime} \mathrm{UTR}$ & 2741 & 382 & 16 & 8 \\
\hline Frameshift & 20 & 2 & 0 & 0 \\
\hline Missense & 3452 & 477 & 27 & 7 \\
\hline Start lost & 8 & 0 & 0 & 0 \\
\hline Stop lost & 8 & 2 & 0 & 0 \\
\hline Stop gained & 19 & 1 & 0 & 0 \\
\hline Splice region variant & 722 & 90 & 3 & 1 \\
\hline Splice acceptor & 19 & 5 & 0 & 0 \\
\hline Splice donor & 30 & 6 & 0 & 0 \\
\hline Coding sequence variant & 4 & 0 & 0 & 0 \\
\hline Inframe deletion & 47 & 1 & 0 & 0 \\
\hline Inframe insertion & 20 & 3 & 0 & 0 \\
\hline Protein altering variant & 1 & 0 & 0 & 0 \\
\hline Synonymous & 77,186 & 704 & 29 & 8 \\
\hline \multicolumn{5}{|l|}{ SNP impact } \\
\hline High & 104 & 16 & 0 & 0 \\
\hline Moderate & 3518 & 481 & 27 & 7 \\
\hline Low & 8343 & 761 & 32 & 9 \\
\hline Modifier & 243,587 & 22,707 & 723 & 323 \\
\hline
\end{tabular}

SNP effect according to Ensembl VEP for putative variants detected using the animals of contrasts (i) and (iii). The results are shown for all filtered variants in the Landrace dataset and variants in differentially expressed genes. Some variants have more than one predicted effect 
(FSCN3). CASA analysis of HIP1 knockout mice has previously shown reduced velocity, amplitude of lateral head displacement and numbers and percentages of motile, rapid and progressive sperm cells [23]. The study of Khatchadourian et al. [23] suggested that HIP1 was involved in sperm motility and morphology by stabilizing actin and microtubules. PRM1 and PRM3 are protamines, which are known for their effect on tight chromatin packaging in sperm cells and association with sperm DNA fragmentation [24]. Sperm motility has also been indirectly associated with protamine through sperm chromatin structure assay parameters [25] and PRM3 deficient mice was shown to exhibit reduced sperm motility [26]. TMEM225 has been shown to regulate protein phosphatase $1 \gamma 2$, which is necessary for sperm capacitation and motility in mice [27], whereas FSCN3 has been associated with capacitation and was proposed a role in rapid cytoskeletal changes [28]. Although none of these genes have previously been associated to hyperactivity, they have been associated to motility. It is not examined or known which type of motility, and our results suggest that the regulation of these genes are affected in the hyperactive fraction of the sperm.

\section{Initial levels of hyperactivity}

The most significant differentially expressed gene in contrast (i), high versus low levels of sperm hyperactivity at the day of ejaculation, was ARFGAP1. The ARFGAP1 protein interacts with ARF1 to regulate membrane traffic between the Golgi and endoplasmic reticulum [29]. ARFGAP1 is suggested to play a role in the physiological function of sperm because of its high expression in testis [29], and another ARF GAP member, SMAP2, has been found important for acrosome formation during spermiogenesis in mice [30]. The results of our study suggest that ARFGAP1 may play a role for the initial levels of hyperactive motility in ejaculates. Whereas $D N L Z$ (discussed above) was the most up-regulated gene in the high hyperactivity group, the novel ENSSSCG00000037477 was the most down-regulated. According to NCBI, this gene is tetratricopeptide repeat protein 37-like (TTC37), which is involved in protein-protein interactions and has mainly been studied in relation with human diseases [31]. This gene has also been associated with fertility in bulls where it was highly expressed in embryos conceived with semen from low fertility sires [32]. The mechanisms behind this gene's involvement in hyperactive motility and fertility is, however, not known.

The testing for over-represented gene ontology pathways showed that a large proportion of the differentially expressed genes from contrast (i) belonged to the term "extracellular exosome". The exosome is a vesicle that is released into the extracellular region, and previous studies have found that epididymal extracellular microvesicles are involved in vertebrate sperm maturation (reviewed by [33]). Moreover, boar seminal plasma exosomes have been associated with sperm motility [34]. Differentially expressed genes from this pathway includes fibronectin 1 (FN1), which has previously been found correlated with midpiece and tail sperm defects in boars [35], and which has also been correlated to total sperm motility in human [36]. FN1 was also differentially expressed at the protein level in boar seminal plasma between ejaculates with good and poor freezability [37]. Other differentially expressed genes from "extracellular exosome" include members of the heat shock protein family (Hsp70) member 4 (HSPA4) and family D (Hsp60) member 1 (HSPD1). HSPA4 is involved in spermatogenesis and a previous study found that mice lacking this gene had a reduced number of spermatozoa and reduced sperm motility [38]. HSPD1 is shown to undergo tyrosine phosphorylation during capacitation in mouse sperm [39] and it is involved in spermatogenesis in human [40]. HSPD1 has, however, not been found associated with sperm motility or hyperactive motility in human [41], and its function in boar sperm hyperactivity needs to be further investigated. In addition to HSPA4 and HSPD1, a heat shock protein regulator also belonging to "extracellular exosome", bcl2 associated athanogene 6 (BAG6), was differentially expressed. BAG6 is the key regulator of heat shock protein HSPA2, which is involved in spermatogenesis [42-44] and associated with sperm motility [45]. Other differentially expressed genes of this pathway include quiescin sulfhydryl oxidase 1 (QSOX1), angiotensin I converting enzyme $(A C E)$, polycystin 1 transient receptor potential channel interacting (PKD1), and CD81 molecule (CD81). QSOX1 has been suggested a role in sperm cell development in mice, based on immunohistochemical association with the sperm acrosome during maturation [46]. Testicular $A C E$ has been found important for sperm motility and male fertility [47] and one of its products, angiotensin II, has been shown to affect sperm motility parameters such as VCL [48], which is one of the CASA parameters describing levels of hyperactivity. PKD1 is involved in testis development $[49,50]$ and is known to cause low sperm quality in men with autosomal dominant polycystic kidney disease [51]. Lack of one homozygous genotype of a PKD1 mutation in stallions also showed its importance for fertility [52], and it has been proposed that PKD1 might interact with CatSpers, which regulate sperm motility (reviewed by [53]). CD81 has previously been found expressed in mouse and bull sperm [54] and shown to be involved in spermatogenesis [55], moreover, it has been implied that a reduced fertility of CD81 knockout mice oocytes is due to failed acrosome reaction in sperm cells [56].

In contrast (i), all genes of the gene ontology term "establishment or maintenance of transmembrane electrochemical gradient" were differentially expressed: ATP1A1, 
$A T P 1 A 2, A T P 1 B 2, A T P 4 A$ and $B A X$. None of these genes were significantly differentially expressed in contrast (ii), suggesting an importance for initial levels of hyperactivity at ejaculation. ATP1A1, ATP1A2 and ATP1B2 belongs to the Na,K-ATPases, which use ATP as energy to make an electrochemical gradient across cell membranes. ATP1A1 has previously been found associated with capacitation in bovine [57], however no studies have indicated such a function of ATP1A2 and ATP1B2. Several studies have however shown that another Na,K-ATPase family member, ATP1A4, is associated with sperm motility, capacitation and hyperactivity through keeping an uneven transmembrane distribution of $\mathrm{Na}^{+}$and $\mathrm{K}^{+}$[58-60]. Our study suggest a similar role for the differentially expressed $\mathrm{Na}, \mathrm{K}-\mathrm{ATPase}$ genes in hyperactivity. BAX is a member of the B-cell lymphoma 2 family and affects cell apoptosis [61], which plays an important role during the development of mature spermatozoa [62]. $B A X$ deficient male mice have been shown to display increased apoptosis and infertility $[63,64]$. Further, $B A X$ has previously been associated with sperm motility in human [65]. The mechanism linking $B A X$ to sperm motility was not suggested, however, it has been shown that apoptosis initiated during spermatogenesis contribute to poor sperm quality, including sperm motility [66].

Eight of the nine genes in "GATOR2 complex" were differentially expressed. GATOR2 regulates mTOR (mechanistic target of rapamycin) signaling by interacting with Rag GTPases. Even though mTOR has previously been found important for spermatogenesis in rats [67], a similar role of the individual differentially expressed genes of this pathway (CASTOR1, MIOS, SEC13, SESN1, SESN2, SZT2, WDR24 and WDR59) has not previously been shown.

Comparison of our results with a high-throughput proteomic study conducted for human sperm motility [19], showed that 57 out of the differentially expressed genes in contrast (i) were the same as their differentially expressed proteins [See Additional File 6]. These genes were to a large degree related to metabolic pathways such as carbohydrate derivate metabolism, lipid metabolic process and protein metabolic process. Moreover, some of the genes has ATP/ADP/GTP/GDP binding activity or ATPase activity: ADP-ribosylation factor-like protein $8 \mathrm{~B}(A R L 8 B)$, cytochrome b5 reductase 3 (CYB5R3), eukaryotic translation elongation factor 2 (EEF2), $\mathrm{H} 1$ histone family member $\mathrm{N}$ testis specific (H1FNT), heat shock protein family A Hsp70 member 2 (HSPA2), $60 \mathrm{kDa}$ heat shock protein mitochondrial (HSPD1), lonprotease homolog mitochondrial (LONP1) and valine-tRNA ligase mitochondrial precursor (VARS). These results are not surprising as sperm cells need energy for being motile, as was also concluded by Amaral et al. [19]. Tektin 5 (TEKT5) was also in common for contrast (i) and the study of Amaral et al. [19]. This gene belongs to pathways such as sperm flagellum and motile cilium, critical pathways for sperm hyperactivity, and has previously also been associated with sperm motility in mouse [68].

Peroxiredoxin-5 mitochondrial (PRDX5), acrosinbinding protein $(A C R B P)$ and apolipoprotein A-I (APOA1) were differentially expressed in contrast (i). This is supported by a previous study examining capacitation related proteins in boar spermatozoa [10]. It was suggested that PRDX5 plays an important role in regulating energy production in the sperm cell and in spermoocyte binding, whereas ACRBP regulates release of acrosin from the acrosome, a proteinase involved in sperm penetration of zona pellucida. APOA1 has previously been found to induce cholesterol efflux in spermatozoa, a process that regulates motility, hyperactivation and capacitation $[69,70]$.

\section{Levels of hyperactivity after storage}

The most significant differentially expressed gene in contrast (iii), high versus low change in levels of sperm hyperactivity between day 0 and $96 \mathrm{~h}$ storage, was SLC4OA1. This gene is involved in iron transport, and previous studies have shown that testicular iron deficiency reduce levels of spermatozoa (reviewed by [71]). The exact function for SLC4OA1 in the resulting levels of sperm hyperactivity is not clear and needs to be further investigated. The most up-regulated gene in the high hyperactivity group was $D N L Z$, whereas the most down-regulated gene was CADPS. CADPS is involved in vesicle exocytosis of various compounds like insulin and neurotransmitters [72] and is tightly coupled to ATP activation and $\mathrm{Ca}^{2+}$ influx [73]. The protein has been found mainly expressed and studied in brain cells of human, mice and rats (e.g. [74, 75]), however it is also expressed in other mice tissues [75], and in pigs, it has been suggested as a candidate gene for body weight [76]. A function in sperm hyperactive motility have not previously been implied, however, it could be explained by its role in ATP activation and $\mathrm{Ca}^{2+}$-influx.

The two most differentially expressed terms of the gene ontology analysis for contrast (iii) were "extracellular space" and "extracellular region". In gene ontology analyses, extracellular region is a parent term of extracellular space, and these are the cell regions where junctions between germ cells and Sertoli cells are located [77]. As germ cells mature and migrate through the testis, a cascade of signal transduction events at the junctions are involved, requiring factors such as cytokines, proteases, protease inhibitors, protein kinases, protein phosphatases, GTPases and junctional complex and extracellular matrix proteins (reviewed by [77]). We have previously shown that numerous genes in this part 
of spermatogenesis are important for different levels of sperm DNA fragmentation [78]. Differentially expressed genes in the current study belonging to the abovementioned pathways include $A D A 2$ (already discussed above), and $\mathrm{C}-\mathrm{X}-\mathrm{C}$ motif chemokine ligand 10 (CXCL10), TNF superfamily member 10 (TNFSF10) and WNT family member 5A (WNT5A) (last three genes discussed under "cytokine activity" below). Moreover, phospholipase A2 group IIA (PLA2G2A) was differentially expressed, a gene whose protein has previously been associated to sperm motility and fertility in human $[19,79]$. Phospholipase A2 is a calcium dependent enzyme which is involved in phospholipid metabolism in membranes and it has been proposed involved in sperm motility also in other species such as sea urchin [80] and fowl [81]. In boars, it has been shown that phospholipase A2 is important for capacitation [82], the process where hyperactive motility is achieved, and the results of this study show that the phospholipase A2 PLA2G2A gene is down-regulated in samples with high hyperactivity after storage.

Another significantly overrepresented gene ontology terms for contrast (iii) was "cytokine activity", which includes the three differentially expressed genes CXCL10, TNFSF10 and WNT5A. Levels of different cytokines have previously been associated to sperm motility and progressive motility in human (e.g. [83, 84]), and our results suggest that cytokines have an effect on hyperactive motility after storage of sperm cells. Cytokines are important for cellular immune responses and are involved in spermatogenesis in the testis by affecting Sertoli germ cell interactions [77]. CXCL1O was down-regulated in the group with high change in levels of hyperactivity after $96 \mathrm{~h}$ storage. It has previously been shown to cause germ cell apoptosis in mice, where CXCL10 knock-out mice had reduced apoptosis [85]. Further, CXCL10 was related to sperm survival in chicken [86]. A role for this gene in sperm hyperactive motility has not previously been indicated, however, previous experiments showed a negative correlation between proportion of apoptotic cells, where apoptosis is initiated during spermatogenesis, and sperm motility in ejaculates [66]. TNFSF10 is an important signaling molecule for proper germ cell apoptosis as knock-out mice showed a dramatically reduced production of mature spermatozoa [87]. Moreover, TNFSF10 was found up-regulated in Landrace boars with high levels of sperm DNA fragmentation in our previous study [78], suggesting that this gene affects several sperm quality parameters. Finally, WNT5A is involved in self-renewal of spermatogonial stem cells [88], a process which is essential for spermatogenesis.

\section{Breed differences}

In this study, Landrace and Duroc samples were analyzed using the same CASA settings, however, after
RNA sequencing, the extreme samples from Duroc did not cluster according to their hyperactive phenotype. The Duroc boars had a higher variability in their hyperactivity levels (Table 1) than the Landrace boars and both the high and low group of Duroc boars had higher levels of hyperactivity compared to Landrace high and low groups. The lack of clustering could suggest that their hyperactivity levels might not be extreme enough, but it could also imply that the settings of the CASA were not appropriate for this breed. For CASA measurements, various instrument settings for different species are most commonly used. For example, the instrument defines and classifies sperm motility patterns differently, and motility characterizations are not identical for different species [89]. It has also been shown previously that different cattle breeds should have different CASA settings due to their large variability in sperm variables [90]. The results of the current study might suggest that breed specific characteristics exists for pigs as well. Our previous study found differences between Landrace and Duroc with regards to hyperactive motility [6]. Landrace sperm cells increased hyperactive motility with 6.3\% from day of collection to $96 \mathrm{~h}$ storage. Duroc, on the other hand, showed higher initial sperm hyperactivity at day of collection and no significant increase after 4 days of storage. Differences in sperm physiology and semen plasma composition for these two breeds have also been found in other studies [91-93]. The results from the current study suggest that breed specific CASA thresholds should be tested.

\section{Variant calling}

The variant calling was done on a limited set of animals, however, a case-control study pointed towards SNP variants that are present in only one of the sample groups and hence associated to sperm hyperactivity. For contrast (i), 278 SNPs were different between the high and low hyperactivity groups. Eighteen of these variants had a moderate or low predicted impact according to Ensemble VEP and were located in genes NEU3, CHRDL2, HMCN1 and uncharacterized genes ENSSSCG00000002261 and ENSSSCG00000026662. NEU3 is a sialidase whose activity has previously been found necessary for capacitation and zona pellucida binding [94]. It is therefore interesting that 13 of the 18 SNPs with low/moderate impact are located in NEU3, including rs318364485 with a predicted deleterious SIFT score (0.05). Moreover, 90 of the modifier impact SNPs are also located in NEU3. The effect should be examined in a larger animal material to see if this SNP could function as a biomarker for sperm hyperactivity.

As this material offers a limited number of animals, additional SNPs could be informative if tested in a larger population. We therefore had a look at SNPs present in the differentially expressed genes. SNPs with a predicted 
high impact were identified in 15 of the differentially expressed genes of contrast (i). Of these, CFAP65 has previously been associated with spermatogenesis and flagellar development [95], and loss of function of the chicken ortholog of CFAP65 has been shown to cause defective sperm motility [96]. Two of the putative high impact SNPs could not be verified in an independent sequencing dataset from the same Landrace population, suggesting that these variants might be false positives or very rare. Even though the other genes with high impact SNPs have not previously been associated with sperm quality, their significant differential expression as well as high impact SNPs make them candidates for further testing as fertility biomarkers.

For contrast (iii), 19 SNPs were different in the casecontrol analysis between the high and low change in hyperactivity level difference between day 0 and $96 \mathrm{~h}$ storage. All of these SNPs were modifier impact, meaning that they are not predicted to have a large impact, however, regulatory SNPs might be located in regions such as 3'UTR [97], which are classified as modifier by VEP, so the identified SNPs could affect levels of hyperactivity after storage through such mechanisms.

\section{Conclusions}

In this study, we performed transcriptome profiling of boar testis tissue from Landrace and Duroc boars based on their levels of sperm hyperactive motility at the day of ejaculation (day 0 ) and on their change in hyperactive motility between day 0 and $96 \mathrm{~h}$ storage. We identified differentially expressed genes and pathways from Landrace boars with high and low levels of hyperactivity on the day of ejaculation (contrast i) and boars with high and low change in hyperactivity between day 0 and $96 \mathrm{~h}$ liquid storage at $18{ }^{\circ} \mathrm{C}$ (contrast iii). Each contrast consisted of three to five animals per group and the animals showed consistently high or low levels of hyperactivity. Overall, our data suggests that $D N L Z$ is important for sperm hyperactivity regardless of storage, whereas $A R F$ GAP1 and SLC4OA1 were the most significant genes for contrasts (i) and (iii), respectively. More than 100,000 filtered high-quality SNPs were identified in the dataset, and a predicted deleterious SNP in the differentially expressed gene NEU3 was detected by case-control analysis. The limited number of animals $(n=3-5$ for each group) could affect the results of this study. The results of this study provide novel insight regarding testis gene expression and its importance for sperm hyperactive motility. Genes and variants identified might be candidate markers useful for predicting boar fertility.

\section{Methods}

\section{Aim and design of the study}

The aim of this study was to identify differential expression of genes in testis tissue from boars with high and low levels of sperm hyperactive motility at ejaculation and change in hyperactive motility after storage. To facilitate this, testis tissue samples were collected at slaughter from AI boars, whose ejaculates had been used for hyperactivity measurements. Samples from boars with repeated extreme high or low sperm hyperactive motility at the day of ejaculation (day 0 ) and high or low change in hyperactive motility between day 0 and $96 \mathrm{~h}$ storage were selected for transcriptome sequencing.

\section{Materials}

Semen collected from 103 purebred Norwegian Landrace boars ( $n=239$ ejaculates) and 88 purebred Duroc boars ( $n=179$ ejaculates) at the AI station run by Norsvin at Hamar, Norway, were the basis for this study. All boars were routinely used for AI and the ejaculates were part of routine collections for the breeding program. The boars were housed in individual $6 \mathrm{~m}^{2}$ pens, fed a standard commercial diet and had access to straw and sawdust as rooting materials. The ejaculate samples were collected between February 21st, 2014 and March 20th, 2015 and the age of the boars at semen collection for sampling ranged from 241 to 1041 days (median age = 338 days). Testis tissue samples were collected after slaughter and immediately frozen in liquid nitrogen, before storage at $-80^{\circ} \mathrm{C}$ until RNA extraction. For Landrace boars with extreme levels of hyperactivity on day 0 , 4 boars with high values and 4 boars with low values were selected (contrast (i)). For Duroc boars with extreme levels of hyperactivity on day 0,3 boars with high levels and 4 boars with low levels were selected (contrast (ii)). For Landrace boars with high versus low changes in levels of hyperactivity between day 0 and $96 \mathrm{~h}$ storage, 5 boars with high levels and 4 boars with low levels were included in the study (contrast (iii)).

\section{Hyperactivity measurements}

The sperm-rich fraction of the ejaculates was collected using the gloved hand technique, as described by Althouse et al. [98]. At the AI station, motility and morphology were subjectively evaluated using phase contrast microscopy (Leica DM 4000B, Leica Microsystems, Wetzlar, Germany) at $37^{\circ} \mathrm{C}$, and ejaculates with $<70 \%$ motile and/or $>20 \%$ morphologically abnormal spermatozoa were discarded. Ejaculates approved by the quality check were diluted to achieve a concentration of $25 \times 10^{6}$ cells/ $\mathrm{mL}$ in Androstar ${ }^{\circ}$ Plus extender (Minitube, 84,184 Tiefenbach, Germany), transferred to airtight tubes containing doses of $89 \mathrm{~mL}$, and stored in liquid conditions at $18^{\circ} \mathrm{C}$ until shipment. Only semen accepted for AI was used in this study. During the $15 \mathrm{~min}$ long transportation from the AI station to the laboratory, the samples were packed in a styrofoam box to ensure a stable temperature. At the laboratory, semen was transferred to 
$15 \mathrm{~mL}$ falcon tubes and the samples were taken for CASA analysis at the day of collection (day 0 ) and after storage at $18{ }^{\circ} \mathrm{C}$ for $96 \mathrm{~h}$ (day 4), as this is the time limit recommended by Norsvin for using the dose. In order to be included in the selection of extreme animals, the boars needed at least three consistent measurements on $\%$ hyperactivity (Table 1 ).

\section{RNA extraction and sequencing}

The RNeasy Midi Kit (Qiagen) was used to extract total RNA from testis tissue. RNA concentrations were measured using a NanoDrop ND-1000 Spectrophotometer (NanoDrop Technologies, DE, USA) and the quality was examined by the 28S:18S rRNA ratio using the RNA 6000 Nano LabChip Kit on 2100 Bioanalyzer (Agilent Technologies, CA, USA). All samples showed RNA integrity numbers $($ RIN) $>7.8$ and a 260/280 ratio $>1.9$. The sequencing was conducted by the Norwegian Sequencing Centre at the Centre for Ecological and Evolutionary Synthesis, University of Oslo (http://www.sequencing.uio.no). Libraries were prepared using TruSeq mRNA stranded HT kit (Illumina) on a Sciclone NGSx liquid automation system (Perkin Elmer). Final library quality check was performed on Fragment Analyser (Advanced Analytical Technologies, Inc) and by qPCR (Kapa Biosciences). Libraries were sequenced on an Illumina HiSeq 4000 according to manufacturer's instructions. Image analysis and base calling were performed using Illumina's RTA software v2.7.7. The reads were 100 base library pair single reads and filtered to remove those with low base call quality using Illumina's default chastity criteria. All samples were run over two sequencing lanes and the number of reads per sample ranged from 65 to 196 million with an average of 98 million reads. The data has been deposited in NCBI's Gene Expression Omnibus (GEO) [99] with GEO series accession number GSE141541.

\section{Processing and differential expression of RNA sequencing data}

Trimmomatic v.0.36 [11] was used to trim reads by removing leading bases with Phred $_{33}$ quality scores $<5$, trailing bases with Phred $_{33}$ quality scores $<3$, using a sliding window of 4 bases and removing the $5^{\prime}$ terminal base if the average Phred $_{33}$ score of the 4 bases was $<15$, and completely discard trimmed reads with less than 36 remaining bases. The high quality reads were subsequently mapped to the pig genome Sscrofa build 11.1 using the Star software v.2.5.2a and default parameters while simultaneously adding unique read groups to the files [100]. Gene prediction coordinates (release 11.1.90) were obtained from Ensembl (http://www.ensembl. org). Samtools v.1.3.1 [101] was used to merge bams from the same sample and to convert bam files to sam files before HTSeq [102] was run with the reverse stranded option to calculate the number of reads mapped to each gene. The differential expression analysis was conducted using the package edgeR v.3.12.1 in the R environment [103]. The two breeds and different contrasts were analyzed separately, and the samples were divided into a high-low hyperactivity level contrast based on their hyperactivity values. Filtering was done to keep only genes that achieved at least one count per million in at least half of the samples, and the data was normalized for differences in the abundance of read counts mapped to genes between samples using the TMM (trimmed mean of M-values) normalization method [104]. This adjusts any differential expression analysis for varying sequencing depths and different library sizes and is part of the basic modeling procedure in edgeR. Variance in gene expression was estimated using a tagwise dispersion model before differential expression was detected with a likelihood ratio test model (option glmFit in edgeR). FDR was calculated using the Bejamini-Hochberg algorithm [105], and an FDR $<0.05$ was considered significant. Gene ontology analyses were run using the R package "goseq" v.1.26.0 [106] using BioMart as implemented in R (biomaRt v.2.30.9) [107] to incorporate pig IDs and the Wallenius approximation method to account for length biases. Pathways with an overrepresented $p$-value $<0.001$ was considered significant.

\section{Variant calling}

Preprocessing of bam files was performed using Picard (sorting, duplicate marking, and indexing) [108]. Variant calling on the Landrace RNA sequencing data was conducted using Samtools v.1.3.1 mpileup and bcftools call [101]. Detected variants were filtered, using bcftools filter and vcftools [109], on alternate allele count $(>2)$, QUAL ( $>25)$, mapping quality $(>10)$ and read depth $(>10)$. Furthermore, both reference and alternate allele had to be present on both strands, and a threshold of at least $4 \mathrm{bp}$ to the next SNP and $10 \mathrm{bp}$ to the next indel was also applied. The filtered variants were subsequently annotated using the Ensembl Variant Effect Predictor (VEP) [110] to classify variants and their impact. SnpSift v.4.3 was subsequently used to estimate case-control (i.e. high versus low hyperactivity) using an allelic model (CC_ALL) and Fisher exact test [111]. Variants were considered significantly different at $p<0.001$. SNP validation was done in silico by matching detected variants to known pig entries collected using VEP and by comparison to an existing independent whole-genome sequence dataset of related boars [78].

\section{Supplementary information}

Supplementary information accompanies this paper at https://doi.org/10. 1186/s12917-020-02373-9.

Additional file 1. Differentially expressed genes for hyperactivity at ejaculation (day 0) in Landrace. The results are presented with Ensembl gene id, gene symbol, gene name, fold change and significance level (FDR). 
Additional file 2. Differentially expressed genes for change in levels of hyperactivity between day 0 and $96 \mathrm{~h}$ storage in Landrace. The results are presented with Ensembl gene id, gene symbol, gene name, fold change and significance level (FDR).

Additional file 3. Variants identified in the Landrace animals of contrasts (i) and (iii). The variants are presented per chromosome with Ensembl VEP information.

Additional file 4 Variant case-control analysis. Chromosome, position, number of homozygous, heterozygous and total variants in cases and controls, Fisher exact test $p$-value for the case control allelic model according to SnpSift (CC_ALL, see Methods), and contrast for significance (Table X1). Consequence, impact, gene id, ensembl gene id, existing variation and SIFT scores are included in Table X2.

Additional file 5. Variants occuring in differentially expressed genes Variants in genes identified for hyperactivity at Day 0 in Landrace (contrast (i), Table X1), change in levels of hyperactivity between day 0 and $96 \mathrm{~h}$ storage in Landrace (contrast (iii), Table X2), and genes in common for contrasts (i) and (iii) (Table X3). The SNPs are presented with Ensembl gene id, gene name, significance level of differentially expressed gene (FDR), chromosome (SSC) and position, effect, impact, existing ID and SIFT score.

Additional file 6. Overlapping results of contrast (i) and proteins involved in human sperm motility. Comparison of our results with the study of Amaral et al. [19] showed that 57 out of the differentially expressed genes in contrast (i) were the same as their differentially expressed proteins.

\section{Abbreviations}

ACE: Angiotensin I converting enzyme; ACRBP: Acrosin-binding protein; ADA: Adenosine deaminase; ADA2: Adenosine deaminase 2; ADP: Adenosine diphosphate; AGGF1: Angiogenic factor with G-patch and FHA domains 1; Al: Artificial insemination; ALH: Amplitude of lateral head displacement; APOA1: Apolipoprotein A-l; ARFGAP1: ADP ribosylation factor GTPase activating protein 1; ARL8B: ADP-ribosylation factor-like protein 8B; ATP: Adenosine triphosphate; ATP1A1: ATPase $\mathrm{Na}+/ \mathrm{K}+$ transporting subunit alpha 1; ATP1A2: ATPase $\mathrm{Na}+/ \mathrm{K}+$ transporting subunit alpha 2; ATP1A4: ATPase $\mathrm{Na}+/ \mathrm{K}+$ transporting subunit alpha 4; ATP1B2: ATPase $\mathrm{Na}+/$ $\mathrm{K}+$ transporting subunit beta 2; ATP4A: ATPase $\mathrm{H}+\mathrm{K}+$ transporting subunit alpha; BAG6: bcl2 associated athanogene 6; BAX: BLC2 associated X, apoptosis regulator; Bp: Base pairs; CAB39: Calcium binding protein 39; CADPS: Calcium dependent secretion activator; CASA: Computer-assisted sperm analysis; CASTOR1: Cytosolic arginine sensor for mTORC1 subunit 1; CatSper: Cation channel of sperm; CCDC187: Coiled-coil domain containing 187; CD81: CD81 molecule; CFAP65: Cilia and flagella associated protein 65; CHRDL2: Chordin like 2; CXCL10: C-X-C motif chemokine ligand 10; CYB5R3: Cytochrome b5 reductase 3; DNLZ: DNL-type zinc finger; EEF2: Eukaryotic translation elongation factor 2; FDR: False discovery rate; FN1: Fibronectin 1; FSCN3: Fascin-3; GDP: Guanosine diphosphate; GEO: Gene Expression Omnibus; GGNBP2: Gametogenetin binding protein 2; GTP: Guanosine triphosphate; H1FNT: H1 histone family member N testis specific; HIP1: Huntington interacting protein 1 gene; HMCN1: Hemicentin 1; Hsp70: Heat shock protein 70 kilodalton; HSPA2: Heat shock protein family A Hsp70 member 2; HSPA4: Heat shock protein family A (Hsp70) member 4; HSPA9: Heat shock protein family A Hsp70 member 9; HSPD1: $60 \mathrm{kDa}$ heat shock protein mitochondrial; LIN: Inearity; LONP1: Lonprotease homolog mitochondrial; MIOS: MEIOSIS regulator for oocyte development; mTOR: Mechanistic target of rapamycin; NEU3: Neuraminidase 3; NUTM1: NUT midline carcinoma family member 1; PPIG: Peptidylprolyl isomerase G; PKD1: Polycystin 1 transient receptor potential channel interacting; PLA2G2A: Phospholipase A2 group IIA; PRDX5: Peroxiredoxin-5 mitochondrial; PRM1: Protamine 1; PRM3: Protamine 3; PRMT2: Protein arginine methyltransferase 2; QSOX1: Quiescin sulfhydryl oxidase 1; RADIL: Rap associating with DIL domain; RAVER1: Ribonucleoprotein PTB binding 1; RIN: RNA integrity number; RNA: Ribonucleic acid; RPS9: Ribosomal protein S9; RUVBL1: RuvB like AAA ATPase 1; SD: Standard deviation; SEC13: SEC13 homolog nuclear pore and COPII coat complex component; SESN1: Sestrin 1; SESN2: Sestrin 2; SLC40A1: Solute carrier family 40 member 1; SMAP2: Small arfGAP2; SZT2: KICSTOR complex subunit; TEKT5: Tektin 5; TMEM225B: Transmembrane protein 225B; TMM: Trimmed mean of M-values; TNFSF10: TNF superfamily member 10;

TTC37: Tetratricopeptide repeat protein 37-like; UTR: Untranslated region; VARS: Valine-tRNA ligase mitochondrial precursor; VEP: Ensembl variant effect predictor; VCL: Curvilinear velocity; WDR24: WD repeat domain 24; WDR59: WD repeat domain 59; WNT5A: WNT family member 5A; WOB: Wobble

\section{Acknowledgements}

The authors want to thank BioBank AS for collecting and storing samples, the Inland Norway University of Applied Sciences for providing lab facilities, the Centre for Integrative Genetics (CIGENE) at the Norwegian University of Life Sciences for providing lab and computer facilities, and the Norwegian Sequencing Centre at Centre for Ecological and Evolutionary Synthesis (CEES), University of Oslo, for performing the sequencing. We are also grateful to the semen collectors and laboratory technicians at Norsvin, Hamar, for taking and processing samples for motility analyses.

\section{Authors' contributions}

MvS conducted RNA extraction, analyzed the data and drafted the paper. NHT was involved in hyperactive motility analyses and contributed to writing the paper. AHG was involved in planning the project, supervised hyperactive motility analyses and contributed to writing the paper. DIV was involved in supervision and contributed to writing the paper. FDM was involved in planning the project, supervision and contributed to writing the paper. TTZ conducted hyperactive motility analyses. EG was involved in planning the project, supervision and contributed to writing the paper. All authors read and approved the final manuscript.

\section{Funding}

The current study was financed by the Norwegian Research Council (Grant number 207568) and Norsvin SA. The funding bodies had no role in the design of the study or the collection, analysis, or interpretation of data or in writing the manuscript.

\section{Availability of data and materials}

The datasets generated and analyzed during the current study are available in the additional files and in NCBI's GEO database with accession number GSE141541.

\section{Ethics approval and consent to participate}

All animals were cared for in line with laws, internationally recognized guidelines and regulations for keeping pigs in Norway (The Animal Protection Act of December 20th, 1974, the Animal Welfare Act of June 19th, 2009 and the Regulations for keeping of pigs in Norway of February 18th, 2003). The animals used in this study were Al boars kept as a routine by Norsvin's breeding program. Ejaculate samples used in this study were part of routine collections, and testis tissue samples were taken after regular slaughter, meaning no ethics committee approval was needed. No animal experiments have been conducted in the scope of this research.

\section{Consent for publication}

Not applicable.

\section{Competing interests}

The authors declare that they have no competing interests.

\section{Author details}

${ }^{1}$ Norsvin SA, 2317 Hamar, Norway. ${ }^{2}$ Department of Biotechnology, Inland Norway University of Applied Sciences, 2318 Hamar, Norway. ${ }^{3}$ Centre for Integrative Genetics (CIGENE), Department of Animal and Aquacultural Sciences, Faculty of Biosciences, Norwegian University of Life Sciences, 1432 Ås, Norway.

Received: 23 January 2020 Accepted: 13 May 2020

Published online: 26 May 2020

\section{References}

1. Didion BA. Computer-assisten semen analysis and its utility for profiling boar semen samples. Theriogenology. 2008;70(8):1374-6. 
2. Verstegen J, Iguer-Ouada M, Onclin K. Computer assisted semen analyzers in andrology research and veterinary practice. Theriogenology. 2002;57:14979.

3. Mortimer ST. A critical review of the physiological importance and analysis of sperm movement in mammals. Hum Reprod Update. 1997;3(5):403-39.

4. Suarez SS. Control of hyperactivation in sperm. Hum Reprod Update. 2008; 14(6):647-57.

5. Schmidt H, Kamp G. Induced hyperactivity in boar spermatozoa and its evaluation by computer-assisted sperm analysis. Reproduction. 2004;128: 171-9.

6. Tremoen NH, Gaustad AH, Andersen-Ranberg I, van Son M, Zeremichael T, Frydenlund K, Grindflek E, Våge DI, Myromslien FD. Relationship between sperm motility characteristics and ATP concentrations, and association with fertility in two different pig breeds. Anim Reprod Sci. 2018;193:226-34.

7. Singh AP, Rajender S. CatSper channel, sperm function and male fertility. Reprod BioMed Online. 2015;30(1):28-38.

8. Vicente-Carrillo A, Álvarez-Rodrìguez M, Rodríguez-Martínez H. The CatSper channel modulates boar sperm motility during capacitation. Reprod Biol. 2017;17(1):69-78.

9. Dorin JR. Novel phenotype of mouse spermatozoa following deletion of nine $\beta$-defensin genes. Asian Journal of Andrology. 2015;17(5):716-9.

10. Kwon WS, Rahman MS, Lee JS, Kim J, Yoon SJ, Park YJ, You YA, Hwang S, Pang MG. A comprehensive proteomic approach to identifying capacitation related proteins in boar spermatozoa. BMC Genomics. 2014;15:897.

11. Bolger AM, Lohse M, Usadel B. Trimmomatic: a flexible trimmer for Illumina sequence data. Bioinformatics. 2014;31(15):2114-20.

12. Warr A, Affara N, Aken B, Beiki H, Bickhart DM, Billis K, Chow W, Eory L, Finlayson HA, Flicek $P$ et al: An improved pig reference genome sequence to enable pig genetics and genomics research. bioRxiv 2019.

13. van Son M, Enger EG, Grove H, Ros-Freixedes R, Kent MP, Lien S, Grindflek E. Genome-wide association study confirm major QTL for backfat fatty acid composition on SSC14 in Duroc pigs. BMC Genomics. 2017;18(1):369.

14. Mortimer ST, Swan MA, Mortimer D. Effect of seminal plasma on capacitation and hyperactivation in human spermatozoa. Hum Reprod. 1998;13(8):2139-46.

15. Apić J, Stančić I, Vakanjac S, Radović I, Milovanović A, Barna T, Maletić M. Influence of the protein content of boar seminal plasma on spermatozoa viability, motility and acrosome integrity in diluted semen stored for 3 days. Anim Reprod. 2016;13(1):36-41.

16. Zhai P, Vu MT, Hoff KG, Silberg JJ. A conserved histidine in human DNLZ/ HEP is required for stimulation of HSPA9 ATPase activity. Biochem Biophys Res Commun. 2011;408(4):589-94.

17. Zhai P, Stanworth C, Liu S, Silberg JJ. The human escort protein Hep binds to the ATPase domain of mitochondrial hsp70 and regulates ATP hydrolysis. J Biol Chem. 2008;283(38):26098-106.

18. Hashemitabar M, Sabbagh S, Orazizadeh M, Ghadiri A, Bahmanzadeh M. A proteomic analysis on human sperm tail: comparison between normozoospermia and asthenozoospermia. J Assist Reprod Genet. 2015; 32(6):853-63.

19. Amaral A, Paiva C, Parrinello CA, Estanyol JM, Ballescà JL, Ramalho-Santos J, Oliva R. Identification of proteins involved in human sperm motility using high-throughput differential proteomics. J Proteome Res. 2014;13(12):5670-84.

20. Shen MR, Linden J, Chiang PH, Chen SS, Wu SN. Adenosine stimulates human sperm motility via A2 receptors. J Pharm Pharmacol. 1993;45(7):650-3.

21. Fénichel $P$, Gharib A, Emiliozzi C, Donzeau M, Ménézo Y. Stimulation of human sperm during capacitation in vitro by an adenosine agonist with specificity for A2 receptors. Biol Reprod. 1996;54(6):1405-11.

22. Adeoya-Osiguwa SA, Fraser LR. Capacitation state-dependent changes in adenosine receptors and their regulation of adenylyl cyclase/cAMP. Mol Reprod Dev. 2002;63(2):245-55

23. Khatchadourian K, Smith CE, Metzler M, Gregory M, Hayden MR, Cyr DG, Hermo L. Structural abnormalities in spermatids together with reduced sperm counts and motility underlie the reproductive defect in HIP1-/mice. Gamete Biology. 2006;74(3):341-59.

24. Aoki WW, Moskovtsev SI, Willis J, Liu L, Mullen BM, Carrell DT. DNA integrity is compromised in protamine-deficient human sperm. J Androl. 2013;26(6):741-8.

25. Giwercman A, Richthoff J, Hjøllund H, Bonde JP, Jepson K, Frohm B, Spano $M$. Correlation between sperm motility and sperm chromatin structure assay parameters. Fertil Steril. 2003;80(6):1404-12.

26. Grzmil P, Boinska D, Kleene KC, Adham I, Schlüter G, Kämper M, Buyandelger B, Meinhardt A, Wolf S, Engel W. Prm3, the fourth gene in the mouse protamine gene cluster, encodes a conserved acidic protein that affects sperm motility. Biol Reprod. 2008;78(6):958-67.

27. Matsuura M, Yogo K. TMEM225: a possible protein phosphatase 1Y2 (PP1 Y2) regulator localizes to the equatorial segment in mouse spermatozoa. Mol Reprod Dev. 2015;82(2):139-48.

28. Baker MA, Reeves G, Hetherington L, Aitken RJ. Analysis of proteomic changes associated with sperm capacitation through the combined use of IPG-strip pre-fractionation followed by RP chromatography LC-MS/MS analysis. Proteomics. 2010;10(3):482-95.

29. Zhang C, Yu Y, Zhang S, Liu M, Xing G, Wei H, Bi J, Liu X, Zhou G, Dong C, et al. Characterization, chromosomal assignment, and tissue expression of a novel human gene belonging to the ARF GAP family. Genomics. 2000;63(3):400-8.

30. Funaki T, Kon S, Tanabe K, Natsume W, Sato S, Shimizu T, Yoshida N, Wong WF, Ogura A, Ogawa T, et al. The Arf GAP SMAP2 is necessary for organized vesicle budding from the trans-Golgi network and subsequent acrosome formation in spermiogenesis. Mol Biol Cell. 2013;24(17):2633-44.

31. Hartley JL, Zachos NC, Dawood B, Donowitz M, Forman J, Pollitt RJ, Morgan NV, Tee L, Gissen P, Kahr WH, et al. Mutations in TTC37 cause trichohepatoenteric syndrome (phenotypic diarrhea of infancy). Gastroenterology. 2010;138(7):2388-98.

32. Kropp J, Carrillo JA, Namous H, Daniels A, Salih SM, Song J, Khatib H. Male fertility status is associated with DNA methylation signatures in sperm and transcriptomic profiles of bovine preimplantation embryos. BMC Genomics 2017. 2017; 18:280

33. Sullivan R. Epididymosomes: Role of extracellular microvesicles in sperm maturation. Front Biosci (Scholar edition). 2016;8:106-14.

34. Du J, Shen J, Wang Y, Pan C, Pang W, Diao H, Dong W. Boar seminal plasma exosomes maintain sperm function by infiltrating into the sperm membrane. Oncotarget. 2016;7(37):58832-47.

35. González-Cadavid V, Martins JA, Moreno FB, Andrade TS, Santos AC, Monteiro-Moreira AC, Moreira RA, Moura AA. Seminal plasma proteins of adult boars and correlations with sperm parameters. Theriogenology. 2014; 82(5):697-707

36. Wennemuth G, Meinhardt A, Mallidis C, Albrecht M, Krause W, Renneberg H, Aumüller $\mathrm{G}$. Assessment of fibronectin as a potential new clinical tool in andrology. Andrologia. 2001;33(1):43-6.

37. Vilagran I, Yeste M, Sancho S, Castillo J, Oliva R, Bonet S. Comparative analysis of boar seminal plasma proteome from different freezability ejaculates and identification of Fibronectin 1 as sperm freezability marker. Andrology. 2015;3(2):345-56.

38. Held T, Barakat AZ, Mohamed BA, Paprotta I, Meinhardt A, Engel W, Adham IM. Heat-shock protein HSPA4 is required for progression of spermatogenesis. Reproduction. 2011;142(1):133-44.

39. Asquith KL, Baleato RM, McLaughlin EA, Nixon B, Aitken RJ. Tyrosine phosphorylation activates surface chaperones facilitating sperm-zona recognition. J Cell Sci. 2004;117:3645-57.

40. Lachance C, Fortier M, Thimon V, Sullivan R, Bailey JL, Leclerc P. Localization of Hsp60 and Grp78 in the human testis, epididymis and mature spermatozoa. Int J Androl. 2010;33(1):33-44.

41. Lachance C, Bailey JL, Leclerc P. Expression of Hsp60 and Grp78 in the human endometrium and oviduct, and their effect on sperm functions. Hum Reprod. 2007;22(10):2606-14.

42. Govin J, Caron C, Escoffier E, Ferro M, Kuhn L, Rousseaux S, Eddy EM, Garin J, Khochbin S. Post-meiotic shifts in HSPA2/HSP70.2 chaperone activity during mouse spermatogenesis. J Biol Chem. 2006;281(49):37888-92.

43. Bromfield E, Aitken RJ, Nixon B. Novel characterization of the HSPA2stabilizing protein BAG6 in human spermatozoa. Mol Hum Reprod. 2015; 21(10):755-69.

44. Sasaki T, Macron E, McQuire T, Arai Y, Moens PB, Okada H. Bat3 deficiency accelerates the degradation of $\mathrm{Hsp} 70-2 / \mathrm{HspA} 2$ during spermatogenesis. J Cell Biol. 2008;182(3):449.

45. Martínez-Heredia J, de Mateo S, Vidal-Taboada JM, Ballescà JL, Oliva R. Identification of proteomic differences in asthenozoospermic sperm samples. Hum Reprod. 2008;23(4):783-91.

46. Wang TE, Li SH, Minabe S, Anderson AL, Dun MD, Maeda Kl, Matsuda F, Chang HW, Nixon B, Tsai PJ. Mouse quiescin sulfhydryl oxidases exhibit distinct epididymal luminal distribution with segment-specific sperm surface associations. Biol Reprod. 2018:99(5):1022-33.

47. Hagaman JR, Moyer JS, Bachman ES, Sibony M, Magyar PL, Welch JE, Smithies O, Krege JH, O'Brien DA. Angiotensin-converting enzyme and male fertility. Proc Nat Acad United States America. 1998;95(5):2552-7. 
48. Ball BA, Gravance CG, Wessel MT, Sabeur K. Activity of angiotensinconverting enzyme (ACE) in reproductive tissues of the stallion and effects of angiotensin II on sperm motility. Theriogenology. 2003;59(3-4):901-14.

49. Nie $X$, Arend LJ. Pkd1 is required for male reproductive tract development. Mech Dev. 2013;130(11-12):567-76.

50. Nie $X$, Arend LJ. Novel roles of $P k d 2$ in male reproductive system development. Differentiation. 2014;87(3-4):161-71.

51. Vora N, Perrone R, Bianchi DW. Reproductive issues for adults with autosomal dominant polycystic kidney disease. Am J Kidney Dis. 2008;51(2): 307-18.

52. Schrimpf R, Gottschalk M, Metzger J, Martinsson G, Sieme H, Distl O. Screening of whole genome sequences identified high-impact variants for stallion fertility. BMC Genomics. 2016;17:288.

53. Garbers DL. Swimming with sperm. Nature. 2001;413:579-81.

54. Jankovicova J, Frolikova M, Sebkova N, Simon M, Cupperova P, Lipcseyova D, Michalkova K, Horovska L, Sedlacek R, Stopka P, et al. Characterization of tetraspanin protein CD81 in mouse spermatozoa and bovine gametes. Reproduction. 2016;152(6):785-93.

55. Kierszenbaum AL, Rosselot C, Rivkin E, Tres LL. Role of integrins, tetraspanins, and ADAM proteins during the development of apoptotic bodies by spermatogenic cells. Mol Reprod Dev. 2006;73(7):906-17.

56. Tanigawa M, Miyamoto K, Kobayashi S, Sato M, Akutsu H, Okabe M, Mekada E, Sakakibara K, Miyado M, Umezawa A, et al. Possible involvement of CD81 in acrosome reaction of sperm in mice. Mol Reprod Dev. 2008;75(1):150-5.

57. Rajamanickam GD, Kastelic JP, Thundathil JC. Na/K-ATPase regulates bovine sperm capacitation through raft- and non-raft-mediated signaling mechanisms. Mol Reprod Dev. 2017;84(11):1168-82.

58. Newton LD, Krishnakumar S, Menon AG, Kastelic JP, van der Hoorn FA Thundathil JC. Na+/K+ATPase regulates sperm capacitation through aMechanism involving kinases and redistribution of ItsTestis-specific isoform. Mol Reprod Dev. 2010;77(2):136-48.

59. Kocak-Toker N, Aktan G, Aykac-Toker G. The role of Na,K-ATPase in human sperm motility. Int J Androl. 2002;25(3):180-5.

60. Jimenez T, Sanchez G, McDermott JP, Nguyen A-N, Kumar TR, Blanco G. Increased Expression of the Na,K-ATPase alpha4 Isoform Enhances Sperm Motility in Transgenic Mice. Biol Reprod. 2011;84(1):153-61.

61. Tikhomirov O, Carpenter G. Bax activation and translocation to mitochondria mediate EGF-induced programmed cell death. J Cell Sci. 2005; 118:5681-90.

62. Billig H, Furuta I, Rivier C, Tapanainen J, Parvinen M, Hsueh AJ. Apoptosis in testis germ cells: developmental changes in gonadotropin dependence and localization to selective tubule stages. Endocrinology. 1995;136(1):5-12.

63. Knudson CM, Tung KS, Tourtellotte WG, Brown GA, Korsmeyer SJ. Baxdeficient mice with lymphoid hyperplasia and male germ cell death. Science. 1995;270(5233):96-9.

64. Rodriguez I, Ody C, Araki K, Garcia I, Vassalli P. An early and massive wave of germinal cell apoptosis is required for the development of functional spermatogenesis. EMBO J. 1997;16(9):2262-70.

65. Mostafa T, Rashed L, Nabil N, Amin R. Seminal BAX and BCL2 gene and protein expressions in infertile men with varicocele. Urology. 2014;84(3):590-5.

66. Shen H-M, Dai J, Chia S-E, Lim A, Ong C-N. Detection of apoptotic alterations in sperm in subfertile patients and their correlations with sperm quality. Hum Reprod. 2002;17(5):1266-73.

67. Xu H, Shen L, Chen X, Ding Y, He J, Zhu J, Wang Y, Liu X. mTOR/P70S6K promotes spermatogonia proliferation and spermatogenesis in Sprague Dawley rats. Reprod BioMed Online. 2016;32(2):207-17.

68. Cao W, ljiri TW, Huang AP, Gerton GL. Characterization of a novel tektin member, TEKT5, in mouse sperm. J Androl. 2011;32(1):55-69.

69. Travis AJ, Kopf GS. The role of cholesterol efflux in regulating the fertilization potential of mammalian spermatozoa. J Clin Invest. 2002;110(6):731-6.

70. Morales CR, Marat AL, Ni X, Yu Y, Oko R, Smith BT, Argraves WS. ATPbinding cassette transporters $A B C A 1, A B C A 7$, and $A B C G 1$ in mouse spermatozoa. Biochem Biophys Res Commun. 2008;376(3):472-7.

71. Sylvester SR, Griswold MD. The testicular iron shuttle: a "nurse" function of the Sertoli cells. J Androl. 1994;15(5):381-5.

72. Miyake K, Ohta T, Nakayama H, Doe N, Terao Y, Oiki E, Nagatomo I, Yamashita Y, Abe T, Nishikura K, et al. CAPS1 RNA editing promotes dense Core vesicle exocytosis. Cell Rep. 2016;17(8):2004-14.

73. Hay JC, Martin TFJ. Resolution of regulated secretion into sequential MgATP-dependent and calcium-dependent stages mediated by distinct cytosolic proteins. J Cell Biol. 1992;119(1):139-51.
74. Speidel D, Varoqueaux F, Enk C, Nojiri M, Grishanin RN, Martin TFJ, Hofmann K, Brose N, Reim K. A family of Ca2+-dependent activator proteins for secretion. J Biol Chem. 2003;278:52802-9.

75. Sadakata T, Wahida M, Morita N, Furuichi T. Tissue distribution of Ca2+ -dependent activator protein for secretion family members CAPS1 and CAPS2 in mice. J Histochem Cytochem. 2007;55(3):301-11.

76. Yang Q, Wu P, Wang K, Chen D, Zhou J, Ma J, Li M, Xiao W, Jiang A, Jiang Y, et al. SNPs associated with body weight and backfat thickness in two pig breeds identified by a genome-wide association study. Genomics. 2018; S0888-7543(18):30329.

77. Mruk DD, Cheng CY. Sertoli-Sertoli and Sertoli-germ cell interactions and their significance in germ cell movement in the seminiferous epithelium during spermatogenesis. Endocr Rev. 2004;25(5):747-806.

78. van Son M, Tremoen NH, Gaustad AH, Myromslien FD, Våge Dl, Stenseth EB, Zeremichael $\Pi$, Grindflek E. RNA sequencing reveals candidate genes and polymorphisms related to sperm DNA integrity in testis tissue from boars. BMC Vet Res. 2017;13(1):362

79. Anfuso CD, Olivieri M, Bellanca S, Salmeri M, Motta C, Scalia M, Satriano C, La Vignera S, Burrello N, Caporarello N, et al. Asthenozoospermia and membrane remodeling enzymes: a new role for phospholipase A2. Andrology. 2015;3(6):1173-82.

80. Loza-Huerta A, Vera-Estrella R, Darszon A, Beltrán C. Certain Strongylocentrotus purpuratus sperm mitochondrial proteins co-purify with low density detergent-insoluble membranes and are PKA or PKC-substrates possibly involved in sperm motility regulation. Biochim Biophys Acta. 2013; 1830(11):5305-15.

81. Froman DP, Feltmann AJ. Fowl (Gallus domesticus) sperm motility depends upon mitochondrial calcium cycling driven by extracellular sodium. Biol Reprod. 2005;72(1):97-101.

82. Roldan ERS, Vazquez JM. Bicarbonate/CO2 induces rapid activation of phospholipase A2 and renders boar spermatozoa capable of undergoing acrosomal exocytosis in response to progesterone. FEBS Lett. 1996;396(2-3): 227-32

83. Gruschwitz MS, Brezinschek R, Brezinschek H-P. Cytokine levels in the seminal plasma of infertile males. J Androl. 1996;17(2):158-63.

84. Perdichizzi A, Nicoletti F, La Vignera S, Barone N, D'Agata R, Vicari E, Calogero AE. Effects of tumor necrosis factor-a on human sperm motility and apoptosis. J Clin Immunol. 2007;27(2):152-62.

85. Jiang Q, Wang F, Shi L, Zhao X, Gong M, Liu W, Song C, Li Q, Chen Y, Wu H, et al. C-X-C motif chemokine ligand 10 produced by mouse Sertoli cells in response to mumps virus infection induces male germ cell apoptosis. Cell Death Dis. 2017:8(10):e3146.

86. Atikuzzaman $M$, Sanz L, Pla D, Alvarez-Rodriguez M, Rubér M, Wright D, Calvete JJ, Rodriguez-Martinez $\mathrm{H}$. Selection for higher fertility reflects in the seminal fluid proteome of modern domestic chicken. Comp Biochem Physiol Part D Genomics Proteomics. 2017;21:27-40.

87. Lin YC, Richburg JH. Characterization of the role of tumor necrosis factor apoptosis inducing ligand (TRAIL) in spermatogenesis through the evaluation of trail gene-deficient mice. PLoS One. 2014;9(4):e93926.

88. Yeh JR, Zhang X, Nagano MC. Wnt5a is a cell-extrinsic factor that supports self-renewal of mouse spermatogonial stem cells. J Cell Sci. 2011;124(Pt 14): 2357-66.

89. Amann RP, Waberski D. Computer-assisted sperm analysis (CASA): Capabilities and potential developments. Theriogenology. 2014;81(1):5-7.

90. Bompart D, Vázquez RF, Gómez R, Valverde A, Roldán ERS, García-Molina A, Soler C. Combined effects of type and depth of counting chamber, and rate of image frame capture, on bull sperm motility and kinematics. Anim Reprod Sci. 2019;209:106169.

91. Waterhouse KE, De Angelis PM, Haugan T, Paulenz H, Hofmo PO, Farstad W. Effects of in vitro storage time and semen-extender on membrane quality of boar sperm assessed by flow cytometry. Theriogenology. 2004;62:1638-51.

92. Waterhouse KE, Hofmo PO, Tverdal A, Miller RR. Within and between breed differences in freezing tolerance and plasma membrane fatty acid composition of boar sperm. Reproduction. 2006;131:887-94.

93. Saravia F, Núñez-Martìnez I, Morán JM, Soler C, Muriel A, Rodríguez-Martínez $H$, Peña FJ. Differences in boar sperm head shape and dimensions recorded by computer-assisted sperm morphometry are not related to chromatin integrity. Theriogenology. 2007;68(2):196-203.

94. Ma F, Wu D, Deng L, Secrest P, Zhao J, Varki N, Lindheim S, Gagneux P. Sialidases on mammalian sperm mediate deciduous sialylation during capacitation. J Biol Chem. 2012;287(45):38073-9. 
95. Tang S, Wang X, Li W, Xang X, Li Z, Liu W, Li C, Zhu Z, Wang L, Wang J, et al. Biallelic mutations in CFAP43 and CFAP44 cause male infertility with multiple morphological abnormalities of the sperm flagella. Am J Hum Genet. 2017:100(6):854-64.

96. Imsland F, Feng C, Boije H, Bed'hom B, Fillon V, Dorshorst B, Rubin CJ, Liu R, Gao Y, Gu X, et al. The Rose-comb mutation in chickens constitutes a structural rearrangement causing both altered comb morpholoty and defective sperm motility. PLoS Genet. 2012;8:e1002775.

97. Ramírez-Bello J, Jiménez-Morales M. Functional implications of single nucleotide polymorphisms (SNPS) in protein-coding and non-coding RNA genes in multifactorial diseases. Gac Med Mex. 2017;153(2):238-50.

98. Althouse GC, Levis DG, Diehl J. Semen collection, evaluation, and processing in the boar. West Lafayette, Indiana: Purdue University Cooperative Extension Service; 1998.

99. Barrett T, Wilhite SE, Ledoux P, Evangelista C, Kim IF, Tomashevsky M, Marshall KA, Phillippy KH, Sherman PM, Holko M, et al. NCBI GEO: archive for functional genomics data sets—update. Nucleic Acids Res. 2013;41:D991-5.

100. Dobin A, Davis CA, Schlesinger F, Drenkow J, Zaleski C, Jha S, Batut P, Chaisson M, Gingeras TR. STAR: ultrafast universal RNA-seq aligner. Bioinformatics. 2013;29(1):15-21.

101. Li H, Handsaker B, Wysoker A, Fennell T, Ruan J, Homer N, Marth G, Abecasis G, Durbin R, Subgroup GPDP. The sequence alignment/map (SAM) format and SAMtools. Bioinformatics. 2009;25:2078-9.

102. Anders S, Pyl PT, Huber W. HTSeq - a Python framework to work with highthroughput sequencing data. Bioinformatics. 2015;31(2):166-9.

103. Robinson MD, McCarthy DJ, Smyth GK. edgeR: a bioconductor package for differential expression analysis of digital gene expression data. Bioinformatics. 2010;26:139-40.

104. Robinson MD, Oshlack A. A scaling normalization method for differential expression analysis of RNA-seq data. Genome Biol. 2010;11:R25.

105. Benjamini Y, Hochberg Y. Controlling the false discovery rate: a practical and powerful approach to multiple testing. J Royal Stat Soc Series B. 1995; 57(1):289-300.

106. Young MD, Wakefield MJ, Smyth GK, Oshlack A. Gene ontology analysis for RNA-seq: accounting for selection bias. Genome Biol. 2010;11:R14.

107. Durinck S, Spellman P, Birney E, Huber W. Mapping identifiers for the integration of genomic datasets with the R/bioconductor package biomaRt. Nat Protoc. 2009;4:1184-91.

108. Picardtoolkit [http://broadinstitute.github.io/picard/].

109. Danecek P, Auton A, Abecasis G, Albers CA, Banks E, DePristo MA, Handsaker RE, Lunter G, Marth GT, Sherry ST, et al. The variant call format and VCFtools. Bioinformatics. 2011;27(15):2156-8.

110. McLaren W, Gil L, Hunt SE, Riat HS, Ritchie GRS, Thormann A, Flicek P, Cunningham F. The Ensembl variant effect predictor. Genome Biol. 2016;17: 122.

111. Cingolani P, Platts A, Wang LL, Coon M, Nguyen T, Wang L, Land SJ, Ruden DM, Lu X. A program for annotating and predicting the effects of single nucleotide polymorphisms, SnpEff: SNPs in the genome of Drosophila melanogaster strain w1118; iso-2; iso-3. Fly (Austin). 2012;6(2):80-92.

\section{Publisher's Note}

Springer Nature remains neutral with regard to jurisdictional claims in published maps and institutional affiliations.

Ready to submit your research? Choose BMC and benefit from:

- fast, convenient online submission

- thorough peer review by experienced researchers in your field

- rapid publication on acceptance

- support for research data, including large and complex data types

- gold Open Access which fosters wider collaboration and increased citations

- maximum visibility for your research: over $100 \mathrm{M}$ website views per year

At $\mathrm{BMC}$, research is always in progress.

Learn more biomedcentral.com/submissions 